\title{
Direito à participação política de crianças sobre a escola: algo mudaria em função da pandemia?
}

\author{
Heloísa Andreia de Matos Lins ${ }^{1}$; Janaína Cabello² ; Camila S. Borges $^{3}$
}

As crianças são prisioneiros políticos [...]

(Deleuze, 2013: 57-58).

\section{As vozes que ecoam}

Um cenário de recusa e suspeita se instaura no Brasil, entre profissionais da educação, sindicatos e pais, como regra, diante da impossibilidade dos encontros presenciais nas escolas, causada pela pandemia do COVID-19, desde a educação infantil até o ensino superior, sobre as propostas remotas, ou seja, sobre a continuidade do fazer educativo pelas escolas, ainda que seja em contexto de excepcionalidade.

Sabe-se que as discussões a esse respeito estão acontecendo em boa parte dos países, mas por motivos políticos bastante peculiares (principalmente a desconfiança -compartilhada e justificada, aliás- quanto aos governantes brasileiros e às suas afrontas quanto aos direitos trabalhistas, nos últimos anos, dentre outras medidas antipopulares, antiambientais, assim como aos conhecidos interesses mercadológicos/oportunistas das grandes corporações sobre a chamada Educação à Distância, EaD), muitos coletivos passam a se organizar contra a proposta, destacadamente os envolvidos com a educação pública. Os argumentos são variados, mas se remetem, com certa regularidade, à precarização das condições de trabalho docente, ao rebaixamento da "qualidade" dos processos educativos, à intensificação das exclusões e desigualdades (de várias ordens), por exemplo.

Houve, inclusive, a proposta de suspensão dos processos escolares (através da manifestação de muitos docentes, principalmente, e pais), considerando o já exposto e os abusos da lógica curricular, avaliativa e das dinâmicas tradicionais (conteudistas, tecnicistas, etc.) que agora se intensificam a olhos vistos (o que Skliar bem nomeou como "tirania da aprendizagem" em Kohan, Redondo e Skliar, 2020).

Neste sentido, através das imagens e notícias a seguir, buscamos evidenciar uma espécie de relevo, nesse território de forças e hegemonias bastante disputadas, conforme uma concepção cartográfica inspirada em Deleuze e Guattari (1995), sobre uma complexidade de intencionalidades e, da forma como concebemos, da confusão criada sobre os oportunismos, de um lado, e um contexto completamente excepcional como o atual, de outro.

Em sociedades ultracapitalistas e neoliberais como as nossas, os direitos de participação das crianças estão distantes do disposto nos textos da lei (direitos retóricos separados dos direitos vividos, como apontam Harcourt e Hägglund, 2013; Lundy, 2007). Nesse bojo, enfatizamos aqui o nosso ponto de vista sobre a situação do Brasil diante dos desafios da educação e o lugar das infâncias, no momento excepcional da pandemia:

\footnotetext{
Profa. Dra. da Faculdade de Educação da UNICAMP, dos cursos de Graduação e Pós-Graduação em Educação. Membro do Grupo de Pesquisa DIS - Diferenças e Subjetividades em Educação: Estudos Surdos, das questões raciais, de gênero e da infancia, Brasil.

E-mail: hmlins@unicamp.br

2 Doutoranda e mestra pela Faculdade de Educação - UNICAMP, na linha de pesquisa Linguagem e Arte em Educação. Professora do curso de Bacharelado em Tradução e Interpretação de Libras e Língua Portuguesa (TILSP) do Departamento de Psicologia da Universidade Federal de São Carlos (UFSCar). É coordenadora do Grupo de Estudos Diferenças e Surdez em pauta (GEDISp), Brasil.

E-mail: janainacabello@ufscar.br

3 Professora de Educação Especial na Rede Municipal de Campinas. Pedagoga formada pela Unesp-Marília. Mestranda da Faculdade de Educação da USP, Brasil.

E-mail: sunshinecml@gmail.com
}

Soc. Infanc. 4, 2020: 185-288 


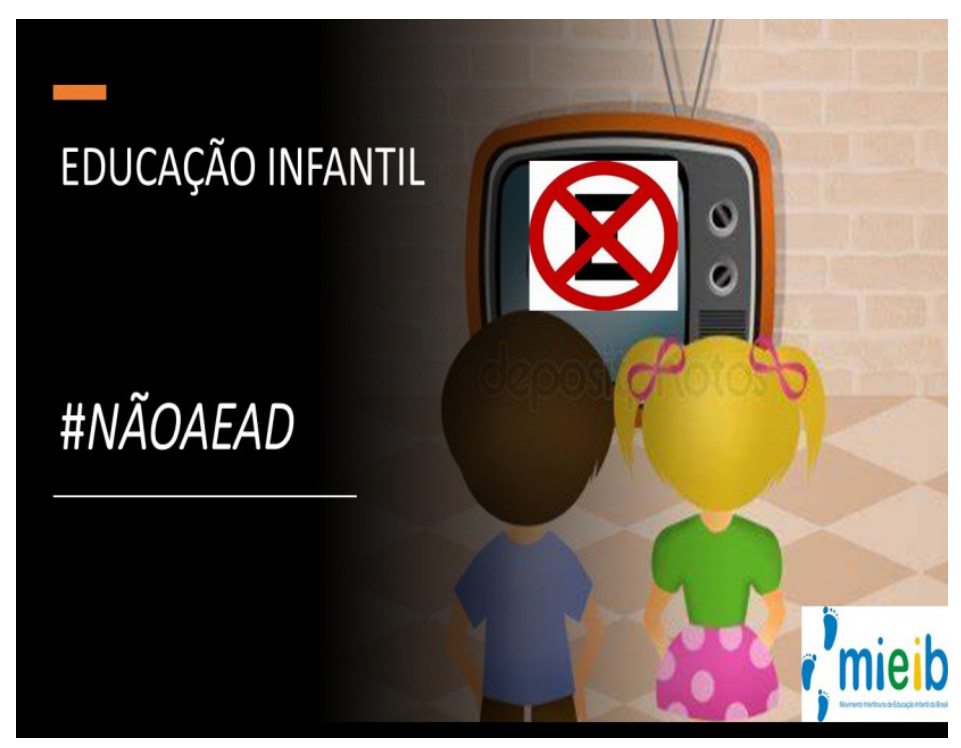

Figura 1. Imagem utilizada por coletivo de educadores. ${ }^{4}$

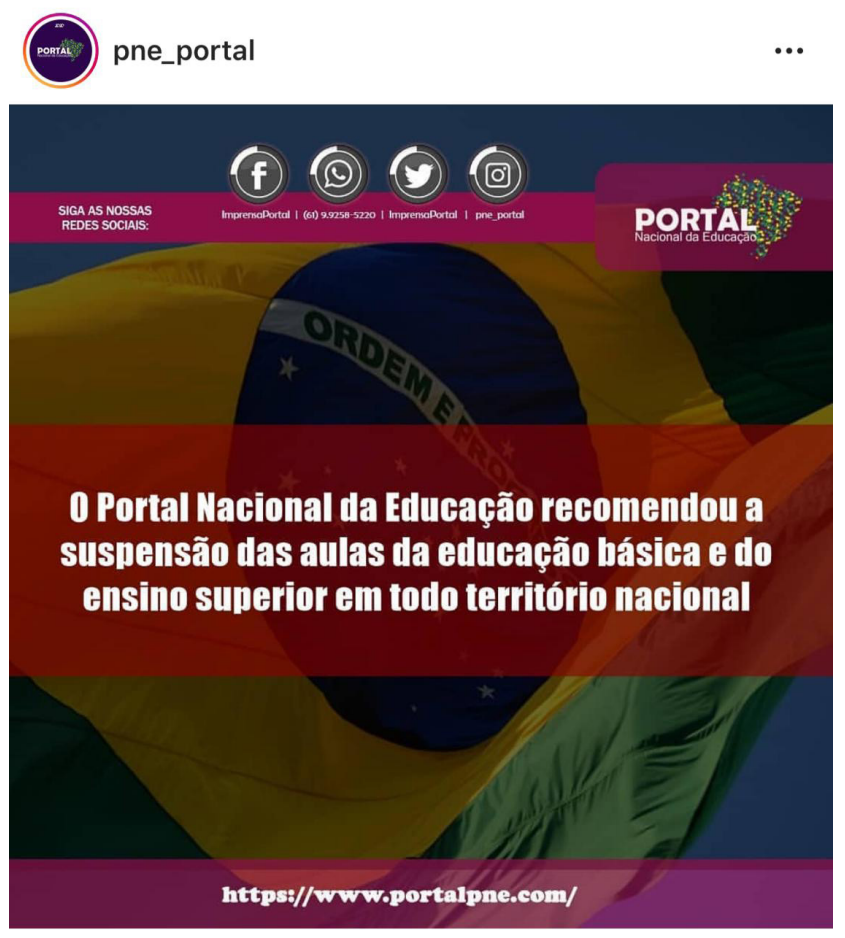

Figura 2. Imagem do Portal Nacional de Educação. ${ }^{5}$

\section{Grupos abutres de educação a distância (EaD) fazem ofensiva durante a pandemia}

By Carta Campinas / in Economia e Politica, Geral, Manchete / on quinta-feira, 16 abr 2020 10:20 PM / 0 Comment

Negócios da educação no Brasil crescem com as crises!

PUBLCIDADE

Figura 3. Imagem de manchete de notícia. ${ }^{6}$

\footnotetext{
Disponível em: https://www.facebook.com/MieibBR/photos/a.951872364905985/2913815968711605/?type=3\&theater Disponível em: https://www.facebook.com/ImprensaPortal/ e https://www.instagram.com/pne portal/?hl=pt-br

Disponível em: https:/cartacampinas.com.br/2020/04/grupos-abutres-de-educacao-a-distancia-ead-fazem-ofensiva-durante-a-pandemia/. Acesso em 08.05.2020.
} 


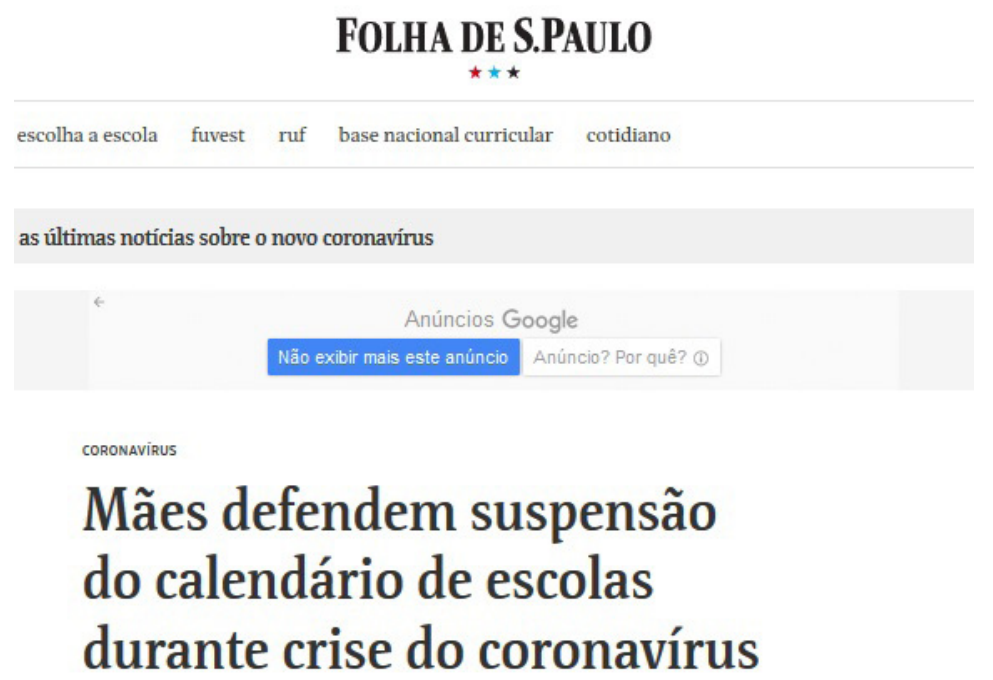

Aulas online não substituem bem experiência escolar, e foco deveria estar no emocional, opinam também especialistas

\section{$\bullet \odot \odot \odot \odot \odot$}

Figura 4. Imagem de manchete de notícia. ${ }^{7}$

\section{Professores e pais acionam Justiça contra ensino remoto \\ Ações pedem que aulas a distância não sejam contadas como horas obrigatórias} POR: Folha de S.Paulo O03 maio 2020, 17h30

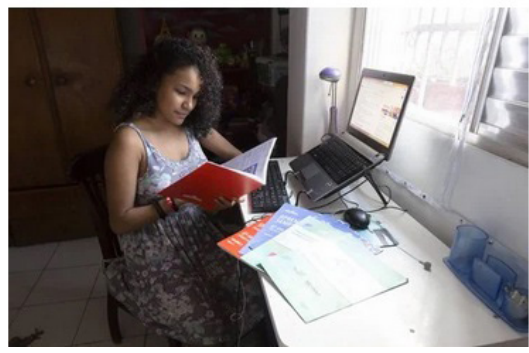

Mais de um mês após o fechamento das escolas em todo o país por conta da pandemia, começam a surgir questionamentos quanto à eficácia de se considerar que as aulas não presenciais e atividades a distância possam substituir o que 0 aluno aprende na escola.

Sobretudo na rede pública, em que o acesso dos estudantes e professores à internet muitas vezes é inexistente ou precário, teme-se - aprofundamento das desigualdades no aprendizado.

Figura 5. Imagem de manchete de notícia. ${ }^{8}$

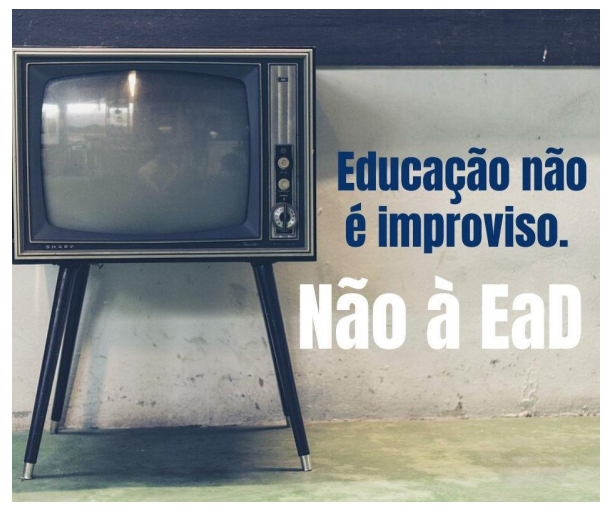

Figura 6. Imagem que ilustra reportagem. ${ }^{9}$

\footnotetext{
Disponível em: https://www1.folha.uol.com.br/educacao/2020/04/maes-defendem-suspensao-do-calendario-de-escolas-durante-crise-do-coronavirus.shtml. Acesso em 08.05.2020.

8 Disponível em: https://maceio.7segundos.com.br/noticias/2020/05/03/168942/professores-e-pais-acionam-justica-contra-ensino-remoto.html. Acesso em 08.05.2020.

9 Disponível em: https://www.appfoz.com.br/pedagogasos-de-foz-lancam-manifesto-por-educacao-de-qualidade-e-contra-improviso-da-ead/. Acesso em 08.05.2020.
} 
Diante desse fluxo de posicionamentos, aqui apresentado num breve recorte, fazemos especial destaque a uma representação vigente sobre as infâncias em sua negatividade constituinte, como apontado por Sarmento (2005), em diálogo com o que destacam também Qvortrup (2010) e Moss (2019), por exemplo. Tal aspecto pode ser sintetizado também pelo meme (em tom supostamente bem humorado!) que circulou nesse período, apontado a seguir:

\section{Aulas online por trás das câmeras}

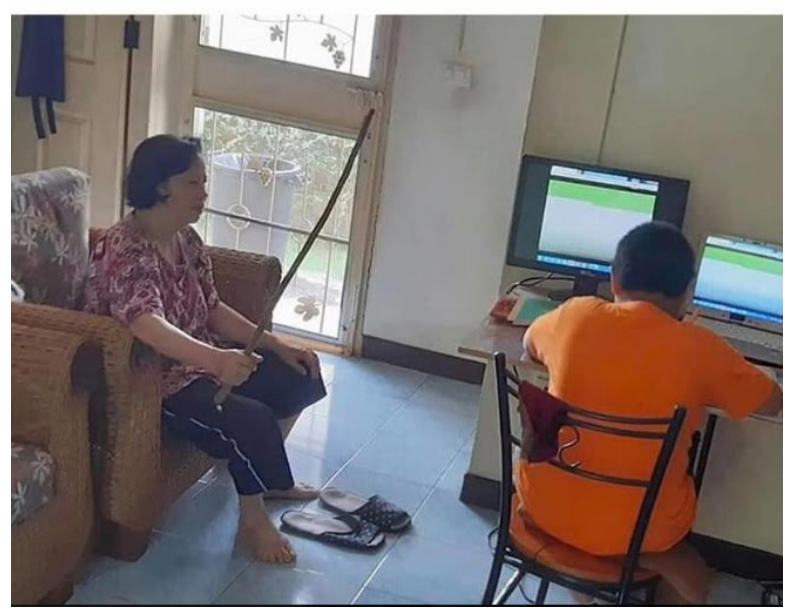

Figura 7. Imagem de meme. ${ }^{10}$

Via de regra, nas imagens, conversas cotidianas, lives e notícias que têm circulado no Brasil, o foco de argumentação dos profissionais da educação e de entidades representativas têm sido as contraposições entre o que seria EaD, o ensino emergencial remoto, a educação e cuidado/ experiências educativas, além do que muitos grupos consideram riscos ao ensino presencial (substituição pela "EaD”, necessidade de suspensão do calendário letivo, desumanização/ precarização do ensino, intensificação das desigualdades, etc), mais destacadamente (preocupações que partilhamos, inclusive). Avolumam-se exemplos, neste sentido:
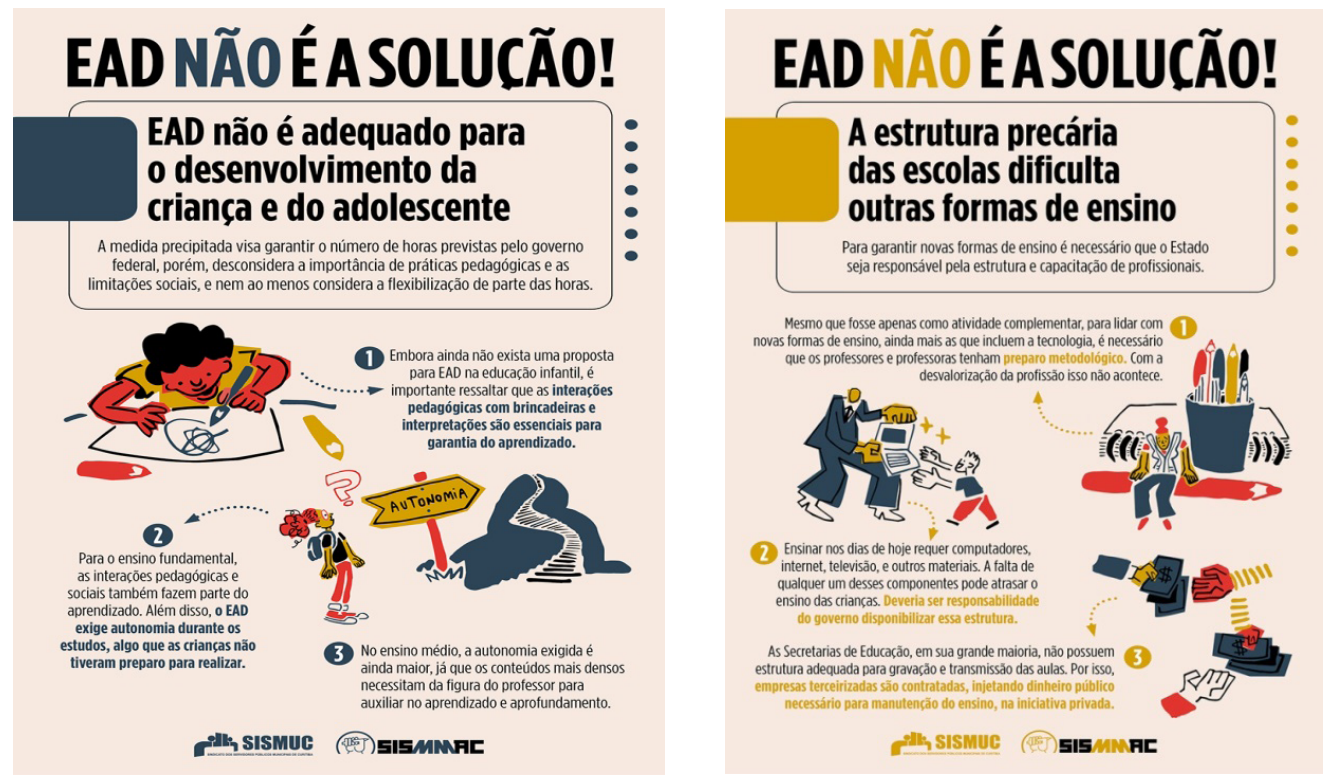

Figuras 8 e 9. Imagens de site de sindicato docente. ${ }^{11}$

Assim, a questão para a qual chamamos a atenção é sobre o fato de não encontrarmos, nesse mapeamento explicitado sobre diversas regiões do país, discussões sobre a necessidade de incorporação das vozes das crianças a respeito de seus processos educativos e possíveis desdobramentos (outros/ distintos das decisões adultas?), a partir

\footnotetext{
10 Disponível em: https://www.facebook.com/Torindopranaochorar/photos/a.985328141514075/3399120420134823/?type=3\&theater. Acesso em 15.6.2020.

11 Disponíveis em: https://sismuc.org.br/noticias/6/educacao/8127/ead-desconsidera-a-dificil-realidade-das-familias-durante-a-pandemia e https:// sismuc.org.br/noticias/6/educacao/8127/ead-desconsidera-a-dificil-realidade-das-familias-durante-a-pandemia. Acesso em 16.6.2020.
} 
daí. Nenhuma urgência mencionada ou reverberada como tema de debate também, no sentido de garantir às crianças a participação nesse processo decisório, como parte dos direitos já dispostos na Convenção dos Direitos das Crianças (CDC), preliminarmente. Não encontramos notícias e campanhas em favor da participação das crianças ou ênfase nos debates que têm sido divulgados na internet, principalmente, por especialistas e envolvidos na área.

Da forma como compreendemos, os acontecimentos afeitos à relação das crianças e seus processos de escolarização estão sendo engendrados sem a devida preocupação sobre a dimensão geracional, por parte dos adultos envolvidos (familiares e profissionais e pelos que realizam as políticas públicas). Nesse contexto, os órgãos governamentais decretam sobre a vida, também escolar, dessas crianças e jovens, sem consultar os principais envolvidos.

Para tratar da participação das crianças no âmbito jurídico, Sanchez (2015) nos ajuda a refletir sobre a questão educacional, quando destaca a forma como os adultos tendem a compreender a Doutrina de Proteção Integral no país, ou seja, de modo apenas parcial (centrados nos direitos de proteção e provisão, em detrimento dos direitos de participação ou direitos de autonomia, conforme também evidenciam Murris, 2017; Caplan et.al, 2016; Percy-Smith e Thomas, 2010, dentre outros estudos).

Diante do exposto, mesmo em momentos de calamidade pública como a que as crianças também estão atravessando, sob os mais variados argumentos que acabam por intensificar a prevalência dos fatores geracionais como importantes mecanismos de exclusão e intensificação de desigualdades nesse ínterim, em democracias frágeis e ameaçadas como é o caso do Brasil atual, percebemos certa naturalização da condição política vivida pelas crianças, também por muitos profissionais da educação pública.

\section{Crianças inauditas: também na pandemia?}

Considerando as limitações de mobilidade no contexto da pandemia, da forma como pudemos mapear e trazer alguns elementos acima demonstrados para discussão, recorremos aos nossos loci de atuação profissional (na educação básica ou no ensino superior), acessamos vários jornais/ mídias e pesquisas durante esse período, dialogamos com os pares, em nível nacional e internacional - através dos grupos online de que fazemos parte - acompanhamos webconferências na área, buscando divulgar também em redes sociais ${ }^{12}$ os principais acontecimentos nesse contexto, além do contato com algumas crianças.

Nesse percurso, consideramos as recomendações da OMS para situações de emergências humanitárias (IASC, 2007) como um elemento essencial para o nosso olhar -através das atualizações da Unesco (2020) diante da pandemia do Covid-19- em que as crianças são concebidas e mencionadas como membros ativos das comunidades e há explicitação da necessidade desse reconhecimento como um dos princípios éticos para quaisquer enfrentamentos a calamidades.

Em linhas gerais, o documento enfatiza a necessidade de continuidade e garantia do direito à educação pelas crianças, através de eliminação de desigualdades assumida como princípio básico:
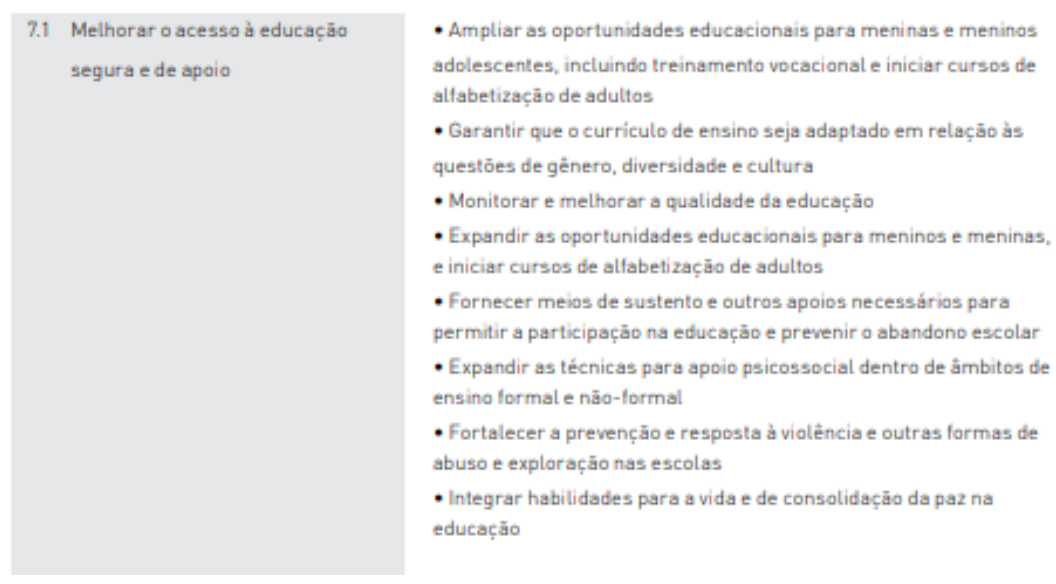

Figura 10. Diretrizes do IASC (2007). ${ }^{13}$

Para muitos estudiosos da infância expoentes na área ${ }^{14}$, assim como para muitos juristas e profissionais que atuam nessa esfera, é bastante enfatizada a manifestação da defesa aos direitos de participação ou direitos políticos das crianças, tal como preconizados pela CDC. De modo geral, argumenta-se por uma visão mais ampla de proteção/

\footnotetext{
Sobre o movimento de (in)formação docente quanto à temática aqui debatida, ver a página desenvolvida pelas autoras: https://www.facebook.com/ ocupaead/

13 Disponível em: https://interagencystandingcommittee.org/system/files/iasc_mhpss_guidelines_portuguese.pdf. Acesso em 15.6.2020..

14 A esse respeito ver, por exemplo, Sarmento (2005,2012, 2015); Sarmento; Fernandes e Tomás (2006, 2007); Qvortrup (2010); Moss (2009, 2019), dentre outros(as).
} 
proteção positiva de desenvolvimento ideal e bem-estar, como defendem Landown e Wernham (2012); Caplan et.al. (2016), isto é, uma abordagem integradora dos direitos infantis (individualidade de direitos e direitos coletivos das crianças como comunidade relacional).

Em suma, trata-se do estabelecimento da condição para participação ativa "em todas as questões que lhe dizem respeito, no âmbito individual ou coletivo, em especial dentro da família, da escola e nas suas comunidades, consolidando a ideia do protagonismo" (Sanchez, 2015: 18). Tratamos, portanto, do direito a ser escutado e considerado em sua existência, ou seja, a garantia de emissão de opiniões (e busca por encaminhamentos) sobre os direitos subjetivos e coletivos que lhe atingem de modo direto ou indireto.

Isto posto, apesar de toda urgência necessária em distintos âmbitos de nosso cotidiano, gerada pelas imposições da pandemia, não temos observado nenhuma alteração sobre a condição de "lockdown dos direitos infantis", principalmente, assim como dos jovens, frente aos saberes-fazeres-poderes adultos.

Para citarmos um exemplo, na cidade de Campinas/SP, as escolas investiram esforços para manter alguma forma de vínculo com a comunidade, com o indicativo de que haveria amplo acesso à internet e aos equipamentos, o que acabou não acontecendo por alegadas questões orçamentárias.

Percebe-se que, como regra, dentre outras precarizações das vidas infantis, enquanto as crianças brasileiras têm sido deixadas à margem dos processos decisórios, uma vez que "elas não assinam textos, não fazem lives e, na maioria das vezes, não são ouvidas sequer dentro das próprias casas" "15, em contextos internacionais há algumas medidas mais favoráveis, ocasionalmente.

Diante do exposto, do modo como concebemos e procuramos aqui enfatizar, temos deixado as possibilidades de as crianças nos ensinarem algo sobre tudo isso que nos atravessa (Tonucci, 2020, 2020b; Kohan, Redondo, Skiliar, 2020; Dussel, 2020) e de tentarmos retribuir com a perspectiva das experiências educativas partilhadas e inventivas, com propostas de aprendizagens que pudessem não se esquecer, por estarem envolvidas de desejos e de sentidos. $\mathrm{O}$ que as crianças proporiam? Esse outro modo de fazer e conceber os "tempos de escola" (assim como o potencial das infâncias) seria uma grande conquista para o período da pandemia, mas certamente para toda a vida social e o fortalecimento do Estado democrático de direito. Uma brecha aqui se abriu e, com aparente vigor renovado, parece ter sido fechada, mais uma vez, pelos adultos com suas decisões unilaterais.

Enquanto as políticas públicas continuam a ignorar os direitos políticos das crianças, o que mais nos surpreende é que sequer isso se torna uma questão a ser colocada como prioridade pelos setores progressistas, como aqui apresentado e argumentado. Causa-nos imensa preocupação o fato de que o protagonismo infantil pareça um constructo teórico assumido por esses grupos, mas ainda distante (quem sabe deixado para um futuro sem pandemia?), numa dicotomia aparente sobre a urgência do enfrentamento nas questões interseccionais, dentre outras, em que a dimensão geracional ainda não é assumida como resistência fundamental, também legítima e urgente. Cada um, por seus motivos, evidentemente, sempre (re) agindo em "nome do bem" das crianças e jogando para o futuro o seu presente (o que se pretende justificar ainda mais, em tempos de catástrofes humanitárias como a atual!).

Intensifica-se a importância, do nosso ponto de vista, sobre o que Sarmento (2005) alertava a respeito do resgate do conceito de geração, diante dos demais fatores de estratificação social e desigualdades: “[...] a geração não dilui os efeitos de classe, de género ou de raça na caracterização das posições sociais, mas conjuga-se com eles [...]” (p. 363).

Além de não nos debruçarmos sobre os preceitos centrais da Coalizão Global pela Educação (UNESCO, 2020) e das recomendações da OMS (IASC, 2007) que trazem protocolos de atuação em torno dos direitos humanos e dos direitos das crianças em tempos de graves crises (no caso do Brasil, ainda que seja o epicentro da pandemia neste momento e o retorno "à normalidade" possa ser letal), como bem aponta também Tonucci (2020; 2020b), estamos nos movendo com ideias velhas e deixando de nos guiar pelas infâncias; deixando de olhá-las, espiá-las e de ouvi-las. Fazer esse gesto não significaria, em absoluto, deixar de combater nenhum risco de intensificação das desigualdades e oportunismos.

\section{Referências bibliográficas}

Caplan, R., Loomis, C., Di Santo, A. (2016). A Conceptual Model of Children's Rights and Community-Based Values to Promote Social Justice Through Early Childhood Curriculum Frameworks. Journal of Childhood Studies. Winter/Hiver, 38(41), 38-46. https://doi.org/10.18357/jcs.v41i3.16305

Deleuze, G. (2013). Conversações. São Paulo: Editora 34.

Deleuze, G., Guattari, F. (1995). Mil platôs: Capitalismo e esquizofrenia. Vol. I. São Paulo: Editora 34.

Dussel, I. (2020). "La clase en pantuflas"- Conversatorio virtual con Inés Dussel ISEP (en línea). https://www.youtube.com/ watch? $=6 x K v C t B C 3 \mathrm{Vs}$, acesso em 19.05.2020.

Harcourt, D., Hägglund, S. (2013). Turning the UNCRC upside down: a bottom-up perspective on children's rights. International Journal of Early Years Education, 21(4), 286-299. https://doi.org/10.1080/09669760.2013.867167

\footnotetext{
Ver por exemplo: https://www.correio24horas.com.br/noticia/nid/o-massacre-as-criancas-durante-a-pandemia/. Acesso 09.05.2020.
} 
IASC (Inter-Agency Standing Committee) (2007). Diretrizes do IASC sobre Saúde Mental e Apoio Psicossocial em Emergências Humanitárias (em línea). https://interagencystandingcommittee.org/system/files/iasc_mhpss_guidelines_portuguese.pdf, acesso em 15.6.2020.

Kohan, W., Redondo, P., Skliar, C. (2020). Conversaciones en la sala de Maestrxs y Profesorxs (en línea).

https://www.youtube.com/watch?v=Y4-b6kvFusU\&feature=emb_err_watch_on_yt, acesso em 08.05.2020.

Lansdown, G., Wernham, M. (2012). Understanding young people's rights to decide: Are protection and autonomy opposing concepts? London: International Planned Parenthood Federation.

Lundy, L. (2007). 'Voice' is not enough: conceptualising Article 12 of the United Nations Convention on the Rights of the Child. British Educational Research Journal. 33(6), 927-942. https://doi.org/10.1080/01411920701657033

Moss, P. (2009). Introduzindo a política na creche: a educação infantil como prática democrática. Psicologia USP, 20(3), 417-436 (en línea).

http://www.scielo.br/pdf/pusp/v20n3/v20n3a07.pdf. Acesso em 12/05/2019.

Moss, P. (2019). Alternative narratives in Early Childhood: An Introduction for Students and Practitioners. London: NY: Routledge.

Murris, K. (2017). Reading two rhizomatic pedagogies diffractively through one another: A Reggio-inspired philosophy with children for the postdevelopmental child. Pedagogy, Culture, \& Society, 25(4), 531-550. 10.1080/14681366.2017.1286681

Percy-Smith, B., Thomas, N. (2010). A Handbook of children and young people's participation: perspectives from Theory and Practice. London: NY: Routledge.

Qvortrup, J. (2010). Infância e política. Cadernos de Pesquisa, (40) 141, 777-792. https://dx.doi.org/10.1590/S010015742010000300006

Sanches, H. C. C. (2015). Desafios para garantia do direito à participação de crianças e adolescentes no sistema judicial brasileiro. RJurFA7, 12(2), 10-32 (en línea). https://periodicos.uni7.edu.br/index.php/revistajuridica/article/download/31/21/, acesso $18 / 05 / 2020$.

Sarmento, M. J. (2005). Gerações e alteridade: interrogações a partir da Sociologia da Infância. Educ. Soc., Campinas, vol. 26, n. 91, p. 361-378, Maio/Ago.

Sarmento, M. J. (2012). A criança cidadã: vias e encruzilhadas. Imprópria. Política e pensamento crítico. UNIPOP, 1(2), 4549 (en línea). https://repositorium.sdum.uminho.pt/bitstream/1822/36755/1/A\%20crian\%C3\%A7a\%20cidad\%C3\%A3.pdf, acesso $18 / 05 / 2020$.

Sarmento, M. J. (2015). Uma agenda crítica para os estudos da criança. Currículo sem Fronteiras, 1(15), 31-49 (en línea). http:// www.curriculosemfronteiras.org/vol15iss1articles/sarmento.pdf, acesso em 18.05.2020.

Sarmento, M. J., Fernandes, N., Tomás, C. (2007). Políticas Públicas e Participação Infantil. Educação, Sociedade e Cultura, 25, 183-206 (en línea). https:/www.fpce.up.pt/ciie/revistaesc/ESC25/ManuelJacintoSarmento.pdf, acesso em 18.05.2020.

Sarmento, M. J., Soares, N. F. , Tomás, C. (2006). Participação social e cidadania activa das crianças. In D. Rodrigues (Org.), Inclusão e Educação. Doze Olhares sobre a Educação Inclusiva (pp. 141-159). São Paulo. Summus Editorial.

Tonucci, F. (2020). Por una buena escuela en tiempo de pandemia. Seminário online Integratek. 25.04.2020.

Tonucci, F. (2020b) A infância e o COVID-19 (en línea). https://www.youtube.com/watch?v=OZ5N-WjqKUA\&feature=youtu. be, acesso em 06.5.2020.

Unesco (2020). Coalizão Global pela Educação (en línea). https://pt.unesco.org/news/unesco-reune-organizacoes-internacionais-sociedade-civil-e-parceiros-do-setor-privado-em-uma, acesso em 16.6.2020.

Unicef (1989). Convenção sobre os direitos da criança (en línea). http://www.unicef.org/brazil/pt/resources_10120.htm, acesso 19.05.2020. 